\title{
Influência do uso de inóculo na estimativa de gás metano dos resíduos orgânicos do aterro sanitário dos municipios do agreste alagoano
}

Influence of the use of inoculum in the estimation of methane gas in organic waste in the landfill of the municipalities of agreste alagoano

Influencia del uso de inóculo en la estimación de gas metano a partir de residuos orgánicos del relleno sanitario en los municipios de agreste alagoano

\author{
Mayco Sullivan Araujo de Santana \\ ORCID: https://orcid.org/0000-0002-8624-107X \\ Universidade Federal de Pernambuco, Brasil \\ E-mail: mayco.sullivan_@hotmail.com \\ Esterphany Cerqueira de Carvalho \\ ORCID: https://orcid.org/0000-0002-6566-5885 \\ Universidade Federal de Pernambuco, Brasil \\ E-mail: esterphanycerqueira28@hotmail.com \\ Nélia Henriques Callado \\ ORCID: https://orcid.org/0000-0002-2393-555X \\ Universidade Federal de Alagoas, Brasil \\ E-mail: nelia.callado@yahoo.com.br
}

\begin{abstract}
Resumo
Uma maneira de aproveitar a energia disponível nos resíduos, estabilizar e reduzir o volume da fração orgânica a ser encaminhado para aterros é através dos digestores anaeróbios. A pesquisa tem por objetivo avaliar a produção de gás metano provenientes da digestão anaeróbia da fração orgânica dos RSU do Aterro Sanitário do Agreste Alagoano, através de ensaios de Potencial Bioquímico do Metano, com e sem a presença do uso de inóculo. Para isso foram utilizados seis reatores de fluxo hidráulico descontínuuo de $1 \mathrm{~L}$, com volume reacional de $400 \mathrm{~mL}$, sendo três reatores com inóculo e outros três com a fração orgânica sem inóculo. O maior potencial foi observado nos reatores com inóculo, de $7926,31 \mathrm{~mL}$, com pico de produção no $10^{\circ}$ dia de operação, e obteve também a maior taxa de produção de metano de $1491,16 \mathrm{~mL} \cdot \mathrm{h}^{-1}$. Os reatores sem inóculo obtiveram menor potencial e taxa de produção de metano, $1020,42 \mathrm{~mL}$ e $28,40 \mathrm{~mL} \cdot \mathrm{h}^{-1}$, sua produção máxima ocorreu ao $30^{\circ}$ dia de operação. Com isso, verifica-se a importância do uso de inóculo para um maior potencial geração de gás metano na digestão anaeróbia de RSU do aterro em estudo, que pode ser utilizado como fonte alternativa de energia para fins domésticos e industriais.
\end{abstract}

Palavras-chave: Metano; Fração orgânica; Inóculo; Potencial energético.

\begin{abstract}
One way to take advantage of the energy available in the waste, stabilize and reduce the volume of the organic fraction to be sent to landfills is through anaerobic digesters. The research aims to evaluate the production of methane gas from the anaerobic digestion of the organic fraction of the MSW of the Sanitary Landfill of Agreste Alagoano, through tests of Methane Biochemical Potential, with and without the use of inoculum. For this purpose, six 1L discontinuous hydraulic flow reactors were used, with a reaction volume of $400 \mathrm{~mL}$, three reactors with inoculum and three others with the organic fraction without inoculum. The greatest potential was observed in the reactors with inoculum, of $7926.31 \mathrm{~mL}$, with peak production on the 10th day of operation, and also obtained the highest methane production rate of $1491.16 \mathrm{~mL} . \mathrm{h}^{-1}$. The reactors without inoculum had lower potential and methane production rate, $1020.42 \mathrm{~mL}$ and $28.40 \mathrm{~mL} \cdot \mathrm{h}^{-1}$, their maximum production occurred on the 30th day of operation. With this, it is verified the importance of the use of inoculum for a greater potential generation of methane gas in the anaerobic digestion of MSW of the landfill under study, which can be used as an alternative source of energy for domestic and industrial purposes.
\end{abstract}

Keywords: Methane; Organic fraction; Inoculum; Energy potential.

\section{Resumen}

Una forma de aprovechar la energía disponible en los residuos, estabilizar y reducir el volumen de la fracción orgánica que se enviará a los rellenos sanitarios es a través de digestores anaeróbicos. La investigación tiene como objetivo evaluar la producción de gas metano a partir de la digestión anaeróbica de la fracción orgánica de los RSU del Relleno Sanitario de Agreste Alagoano, mediante pruebas de Potencial Bioquímico de Metano, con y sin la 
presencia del uso de inóculo. Para ello se utilizaron seis reactores de flujo hidráulico discontinuo de 1L, con un volumen de reacción de $400 \mathrm{~mL}$, tres reactores con inóculo y otros tres con la fracción orgánica sin inóculo. El mayor potencial se observó en los reactores con inóculo, de 7926,31 mL, con pico de producción al décimo día de operación, y también obtuvo la mayor tasa de producción de metano de 1491,16 mL.h ${ }^{-1}$. Los reactores sin inóculo tuvieron menor potencial y tasa de producción de metano, $1020.42 \mathrm{~mL}$ y $28.40 \mathrm{~mL}^{-1}{ }^{-1}$, su producción máxima se dio al día 30 de operación. Con esto, se comprueba la importancia del uso de inóculo para una mayor generación potencial de gas metano en la digestión anaeróbica de RSU del relleno sanitario en estudio, el cual puede ser utilizado como fuente alternativa de energía para fines domésticos e industriales.

Palabras clave: Metano; Fracción orgánica; Inóculo; Potencial energético.

\section{Introdução}

A grande geração de resíduos sólidos urbanos (RSU), originada principalmente pelo desenvolvimento sócio econômico da população mundial, é um dos problemas mais graves observados nos dias atuais. Essa crescente geração se dá principalmente pelo aumento do seu desenvolvimento sócio econômico. Deste modo, estudos sobre gerenciamento de resíduos e seu potencial energético por meio de novas tecnologias merecem atenção, uma vez que representam um método de aproveitamento destes materiais e redução dos efeitos de poluição que podem causar (Damrongsak; Chaichana; Wongsapai, 2017; Gao, et al., 2019).

O descarte de grandes quantidades de resíduos orgânicos causa poluição ambiental significativa e altos custos financeiros no mundo. Em comparação com os métodos tradicionais de descarte (ou seja, aterro, incineração e compostagem), a digestão anaeróbia (DA) é uma tecnologia promissora para gestão de resíduos (Xu, et al., 2018).

A DA é a decomposição bacteriana de materiais orgânicos na ausência de oxigênio. Esse processo biológico gera um gás, chamado de biogás, composto principalmente de metano e dióxido de carbono, que é produzido a partir de matéria-prima, como biossólidos, esterco de gado e materiais orgânicos úmidos (Rogoff \& Screve, 2019).

A digestão anaeróbia se apresenta como uma alternativa para o tratamento dos resíduos orgânicos, proporcionando uma gestão sustentável dos mesmos. Além disso, esse processo dá origem a dois subprodutos, o biogás e o biofertilizante, com alto valor agregado, que podem ser facilmente inseridos na própria cadeia produtiva em que são gerados, resultando em um ciclo eficiente e limpo, com aproveitamento energético e atendimento à legislação (Costa, et al., 2016; Machado, et al., 2018).

O biogás é uma mistura gasosa, resultante do processo de digestão anaeróbia da matéria orgânica, e é considerado um recurso renovável porque faz parte do ciclo biogeoquímico do carbono. É constituído principalmente por metano e dióxido de carbono, com quantidades menores de hidrogênio sulfeto, amônia e vapor de água com traços de hidrogênio e amônia (Dai, Li, Zhang, et al., 2016; Haryanto, et al., 2018).

A influência de fatores na digestão anaeróbia ocorre basicamente de três formas: provocando desequilíbrios entre as populações bacterianas envolvidas no processo, afetando o seu rendimento e a velocidade do processo (De Souza, 1984). A eficiência global do processo de digestão anaeróbia e os teores de metano no biogás dependem fundamentalmente das condições ambientais e operacionais nos reatores anaeróbios (Gueri, 2017).

Os fatores ambientais que influenciam a digestão anaeróbia envolvem, principalmente, temperatura, $\mathrm{pH}$, alcalinidade, macronutrientes adequados (nitrogênio, fósforo e fosfato) e micronutrientes (traços de metais), tempo metabólico adequado e uma fonte de carbono (para síntese e energia). A produção máxima ocorre quando estes parâmetros são escolhidos entre a faixa ótima (Moraes, Zaiat \& Bonomi, 2015; Nogueira, et al., 2015).

Portanto, a qualidade da geração de gás metano na digestão anaeróbia está associada a diversos fatores, dentre eles, temperatura, $\mathrm{pH}$, agitação da biomassa, umidade, sólidos voláteis, inóculo, dentre outros parâmetros, que podem favorecer o desequilíbrio dos micro-organismos envolvidos na biodegradação, e assim o rendimento e a velocidade do processo. 
A escolha de inóculos para o tratamento de resíduos sólidos orgânicos é de extrema importância para possibilitar o aumento na eficiência do processo de biodegradabilidade da matéria orgânica na digestão anaeróbia resultando em maiores rendimentos na produção de biogás.

O processo de inoculação tem como objetivo a redução do tempo de estabilização anaeróbia dos resíduos, por meio do tratamento combinado com vários resíduos com características complementares, em uma única instalação (Magalhães, 2018). A degradação desses compostos orgânicos complexos por processo biológico depende do acompanhamento do ambiente favorável para o crescimento de microrganismos, como também no controle de materiais possivelmente tóxicos. Portanto é necessário propiciar o desenvolvimento de grande quantidade de biomassa microbiana com elevada atividade (Chernicharo, 1997).

O ensaio de Potencial Bioquímico de Metano (BMP) se destina a avaliar a biodegradabilidade dos resíduos com base na produção total de biogás e metano, sob condições ótimas de degradação. O ensaio de BMP é relativamente um método simples e confiável para comparação da extensão e taxa de conversão em metano. Essas propriedades podem ser levado em consideração na avaliação dos sistemas de produção e conversão de biomassa, incluindo matéria-prima seleção; condições de crescimento, colheita e armazenamento; biogásificação; uso de gás; e processamento de resíduos (Chynoweth, et al., 1993).

De acordo com estudo de Liu, et al., (2011), em que foi visto a influência do ajuste de inóculo na digestão anaeróbia de resíduos orgânicos para produção de biogás. Foram analisadas três razões $(0,26 ; 0,36$ e 0,6) no desempenho da DA, mostrando que razões maiores de inóculo pode melhorar a eficiência da digestão.

Saidu, et al., (2013) estudou a influencia da adição de moinho de óleo de palma como inóculo no potencial de geração de biogás de estercos bovinos e verificou que no reator em que continha o inóculo houve uma produção de $41 \%$ de gás metano em comparação com $18 \%$ produzidos no reator sem a adição de inóculo.

Li, et al., (2013) investigaram o BMP e biodegradabilidade de resíduos de cozinha, palha de milho e esterco de frango, sob condições mesofílicas $\left(37^{\circ} \mathrm{C}\right) \mathrm{em}$ sistema batelada utilizando diferentes relações de I/S. Esses autores identificaram que a relação com teor de substrato 3 vezes maior do que o inóculo acarreta em baixo desempenho no que tange à produção de metano.

Lima (2015) analisou alguns tipos de inóculos para a degradação da fração orgânica de resíduos sólidos urbanos e observou que o lodo industrial produziu em uma quantidade maior de metano, em seguida do lodo de tanque séptico e lodo de reator estação de tratamento de esgoto (ETE) e por último lodo de lixiviado de aterro.

Dixon, et al., (2019) investigou o efeito da relação substrato/inóculo nos mecanismos de transformação bioquímica e produção de metano durante a digestão anaeróbia de fração orgânica de RSU, as relações de S/I foram 1, 2 e 3. O ensaio com relação de $\mathrm{S} / \mathrm{I}=1$ produziu o maior rendimento máximo até o dia 37, a relação de $\mathrm{S} / \mathrm{I}=2$ e 3 resultaram em uma maior liberação de ácidos graxos voláteis que $S / I=1$. Isso levou a inibição da metanogênese e menores rendimentos cumulativos de $\mathrm{CH}_{4}$.

Edwiges, et al., (2020) realizaram uma análise do potencial de metano de resíduos orgânicos, através da avaliação da monodigestão anaeróbia semi-contínua. O BMP determinado por frascos de batelada foi de $360 \mathrm{~L}_{\mathrm{N}} \mathrm{CH}_{4} \mathrm{~kg} \mathrm{vs}^{-1}$, com uma biodegradabilidade de 79\%. O rendimento de metano indicou o melhor desempenho com taxa de carga orgânica de 3,0 gVS $\mathrm{L}^{-1} \mathrm{~d}^{-1}$, com $285 \mathrm{~L}_{\mathrm{N}} \mathrm{CH}_{4} \mathrm{~kg} \mathrm{vs}^{-1}$ adicionado, atingindo $79 \%$ da BMP. Com taxa de carga orgânica acima de 3,0 $\mathrm{gVS} \mathrm{L}^{-}$ ${ }^{1} \mathrm{~d}^{-1}$, foi detectada uma acumulação de ácidos graxos voláteis (AGV); em particular, o ácido propiônico foi monitorado e um rendimento reduzido de metano foi detectado. A taxa de produção de biogás foi de $1,55 \mathrm{~L}_{\mathrm{N}} \mathrm{L}^{-1} \mathrm{~d}^{-1}$ e apresentou aumento linear de acordo com os aumentos na carga orgânica.

O gás metano gerado na decomposição da fração orgânica de resíduos sólidos trás efeitos nocivos ao meio ambiente e ao homem e a sua quantificação é importante para medidas de controle e de reaproveitamento para geração de energia elétrica. 
Diante disto, o presente trabalho tem como proposta avaliar, experimentalmente, a produção de gás metano provenientes da digestão anaeróbia da fração orgânica dos resíduos sólidos do Aterro Sanitário do Agreste Alagoano, através da realização de ensaios de Potencial Bioquímico do Metano (BMP), com e sem a presença do uso de inóculo. Verificando assim a intensificação ou retardamento da geração de gás metano nas duas situações.

\section{Metodologia}

O presente trabalho trata-se de uma pesquisa experimental, quali-quantitativa, desenvolvida em laboratório da Universidade Federal de Alagoas (UFAL) a partir de dados obtidos através da decomposição da matéria orgânica presente nos resíduos sólidos urbanos do Agreste de Alagoas.

A fração orgânica é proveniente da composição gravimétrica realizada no aterro sanitário do agreste de Alagoas, que foi construído para atender ao Consorcio Regional de Resíduos Sólidos do Agreste Alagoano (CONAGRESTE). Atualmente recebe resíduos de 29 municípios, com um total de aproximadamente 900 mil habitantes.

A fração orgânica separadas e coletadas na fase de composição gravimétrica, em janeiro de 2020, foram colocadas em sacos hermeticamente fechados, acondicionados em caixas de isopor e encaminhados ao Laboratório de Saneamento Ambiental da UFAL - LSA.

Foi utilizada uma amostra de 2,0kg de resíduos orgânicos que foram misturados e cortados. Em seguida, uma subamostra de 500g de resíduos foi transferida para liquidificador de alta rotação industrial, 2L METVISA modelo LAR2220CC5, e água destilada foi adicionada até atingir um conteúdo final de $20 \%$ de resíduo.

Os ensaios de Produção Bioquímica de Metano (BPM) foram realizados para estimar experimentalmente o potencial de geração de metano dos resíduos orgânicos do aterro do CONAGRESTE.

O ensaio experimental foi conduzido em triplicata, em reatores de fluxo hidráulico descontinuo, para cada amostra com duração de 90 dias de monitoramento. Como reatores, foram utilizados sete frascos de vidro Duran ${ }^{\circledR}$ de $1 \mathrm{~L}$, com volume reacional igual a $400 \mathrm{~mL}$, sendo três reatores (reator 1, 2 e 3) contendo inóculo, outros três reatores (4, 5 e 6) sem a presence de inóculo para comparação da potencialidade de geração de gás metano com o ensaio com a presença de inóculo e um reator (reator 7) só com inóculo para controle do experimento. Para garantir a anaerobiose, o headspace dos reatores foi borbulhado com nitrogênio $\left(\mathrm{N}_{2}\right)$ por um período de 3 minutos a para substituir o ar atmosférico.

Os reatores foram mantidos sob uma temperatura de $35 \pm 1^{\circ} \mathrm{C}$ e rotação de $120 \mathrm{rpm}$ mantidas por uma câmara incubadora refrigerada com agitação orbital (shaker) MARCONI modelo MA830.

O inóculo utilizado no ensaio foi o lodo proveniente de um reator UASB, coletados em uma Estação de Tratamento de Esgoto (ETE) de um condomínio residencial, em Maceió, Alagoas.

O gás metano foi determinado e mensurado através de cromatografia gasosa, segundo metodologia proposta por Maintinguer et al. 2008.

Para o cálculo da determinação da produção de metano foi aplicado o mesmo método que o utilizado por Oliveira (1997) e Steil (2007). Sendo obtidos seguindo os passos descritos a seguir:

- As áreas do metano foram convertidas utilizando a equação padrão da reta em $\mathrm{Mol}$ de $\mathrm{CH}_{4}$;

- Foram acumuladas as concentrações de metano da seguinte forma:

- No tempo 0, a concentração de metano era aquela obtida no headspace do frasco nesse tempo;

- No tempo 1, a concentração de metano era aquela obtida no headspace do frasco nesse tempo, mais a concentração de metano obtida no tempo anterior (zero);

- No tempo 2, a concentração de metano era aquela obtida no headspace do frasco nesse tempo; mais a concentração de metano obtida no tempo 0 , e no tempo 1 . E assim sucessivamente. 
- Os valores de metano obtidos na amostra de $1 \mathrm{~mL}$ sacada dos reatores foram convertidos para o headspace de cada frasco através da seguinte Equação 1:

$$
\left[\mathrm{CH}_{4}\right]=\frac{\left[\mathrm{CH}_{4}\right]_{\text {na amostra }} \mathrm{X} \text { vol do headspace }}{\text { Vol de amostragem }}
$$

Em que,

$\left[\mathrm{CH}_{4}\right]_{\text {no headspace }(\mathrm{mol})}=$ Quantidade de metano no headspace;

$\left[\mathrm{CH}_{4}\right]_{\text {na amostra }}=$ Quantidade de metano na amostra injetada no cromatógrafo;

Volume do headspace $=$ Volume total do headspace do reator;

Volume de amostragem = Volume sacado no reator e injetado no cromatógrafo;

- Os volumes acumulados de metano nos headspace em mol/L, foram convertidos em $\mathrm{L}_{\mathrm{CH}} / \mathrm{L}$ através da equação geral dos gases:

$$
\mathrm{PV}=\mathrm{nRT}
$$

Em que,

$\mathrm{P}=696,7 \mathrm{mmHg}$;

$\mathrm{V}=$ Volume a ser convertido;

$\mathrm{n}=$ Número de mol do gás;

$\mathrm{R}=62,3 \mathrm{mmHg} \mathrm{T}=237+26^{\circ} \mathrm{C}$.

- Para ajuste dos dados experimentais, obtidos através das médias de produção de metano CH4 dos reatores em batelada, será utilizado o Software Origin Pro 8. A máxima produção de metano será estimada através do ponto de inflexão - ponto no qual ocorre a taxa máxima de variação da função - dos modelos de regressão não-linear ajustados aos dados observados.

O acompanhamento do gás metano foi realizado, inicialmente, 3 vezes por semana até que se obteve uma alta produção e passou a ser monitorado 5 vezes por semana. Os gases foram mensurados 24 horas após a montagem e partida dos reatores.

\section{Resultados e Discussão}

Os reatores foram desativados conforme a produção de metano atingiu a estabilidade, e os tempos de duração das operações estão apresentados na Tabela 1. O momento de estabilização foi determinado avaliando-se a curva de produção acumulada de metano ajustada ao modelo de Gompertz modificado, e caracterizado pela obtenção de volumes de metano acumulado semelhantes em análises consecutivas.

Tabela 1 - Duração de operação dos reatores na análise.

\begin{tabular}{cc}
\hline Reator & Tempo de Operação (dias) \\
\hline 1,2 e 3 & 64 \\
4,5 e 6 & 95
\end{tabular}

Fonte: Autores (2021). 
Os reatores 1, 2 e 3, que possuíam inóculo, encerraram primeiro a produção de metano. Já os reatores 4 , 5 e 6, que não possuíam inóculo, foram mantidos em operação por mais tempo a fim de verificar se ainda haveria um aumento na produção de metano.

Nas Figuras 1 e 2 estão apresentadas os volumes médios acumulados e diários de metano produzidos pelos reatores que tinha a presença de inóculo.

Figura 1 - Produção acumulada média de CH4 nos reatores COM Inóculo.

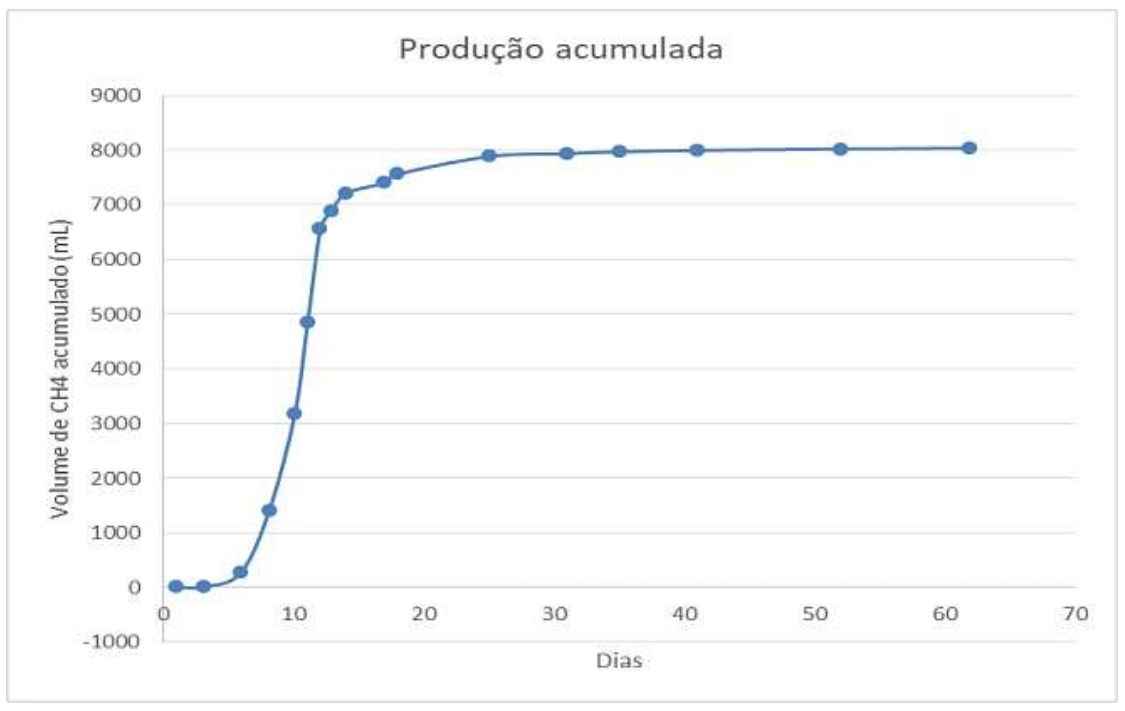

Fonte: Autores (2021).

Figura 2 - Produção diária de CH4 nos reatores COM Inóculo.

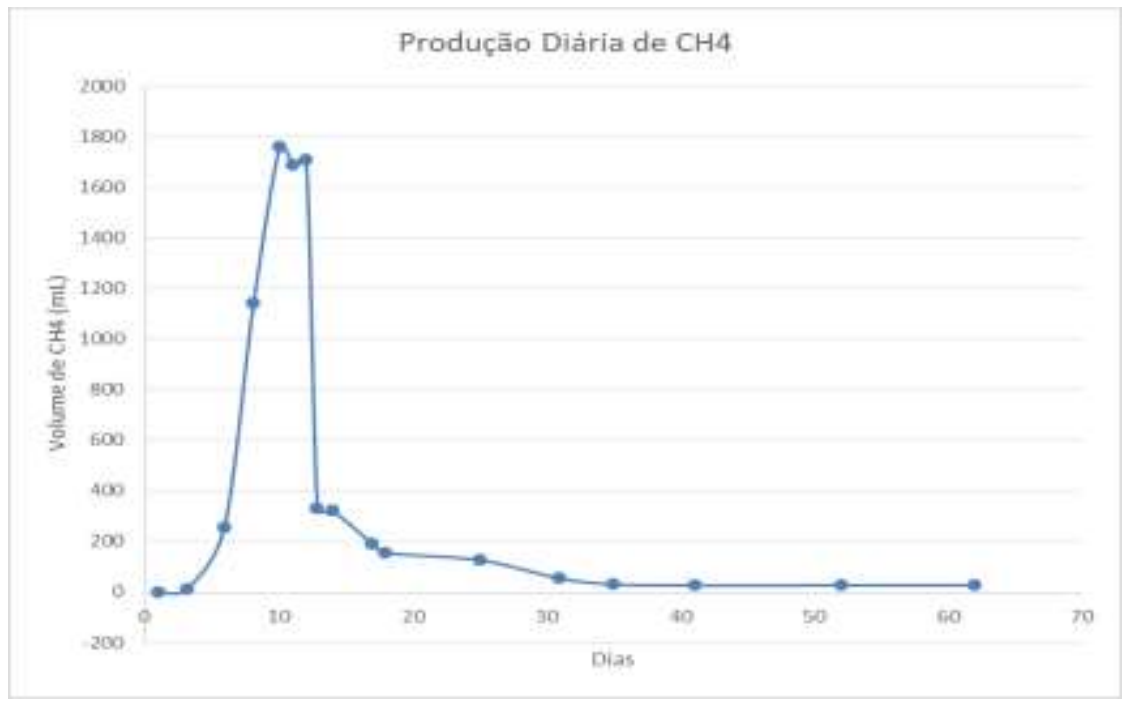

Fonte: Autores (2021).

As Figuras 3 e 4 estão apresentados os volumes médios acumulados e diários de metano produzidos pelos reatores que não possui a presença de inóculo. 
Figura 3 - Produção acumulada média de CH4 nos reatores SEM Inóculo.

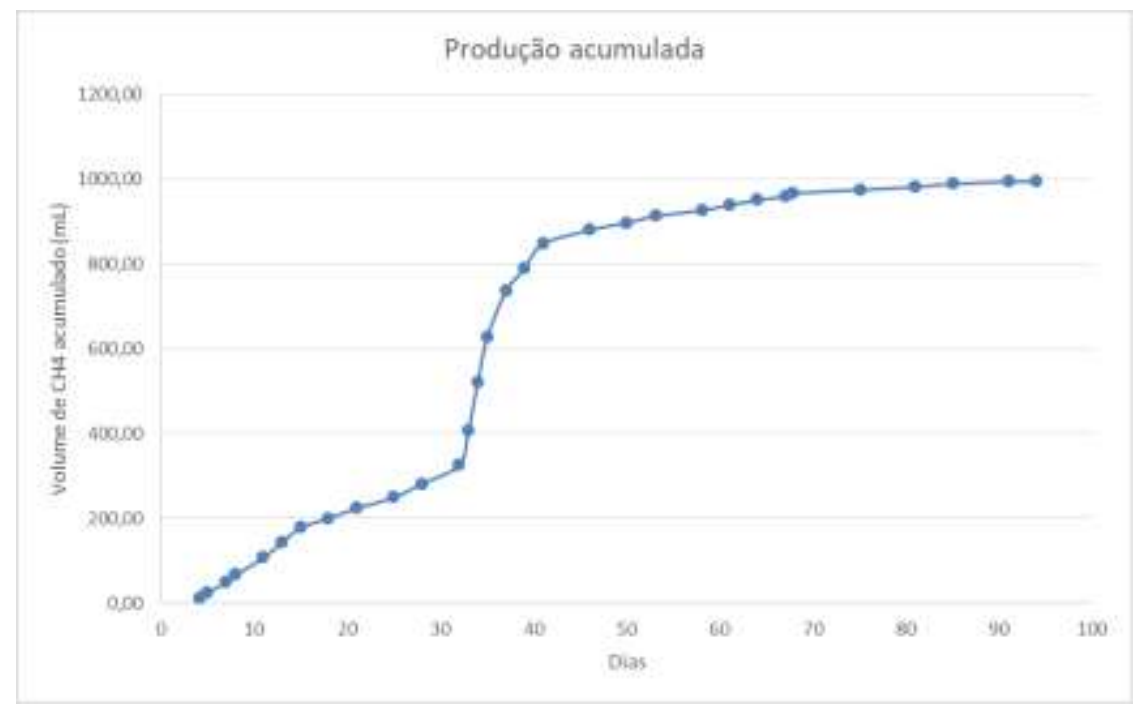

Fonte: Autores (2021).

Figura 4 - Produção diária de CH4 nos reatores SEM Inóculo.

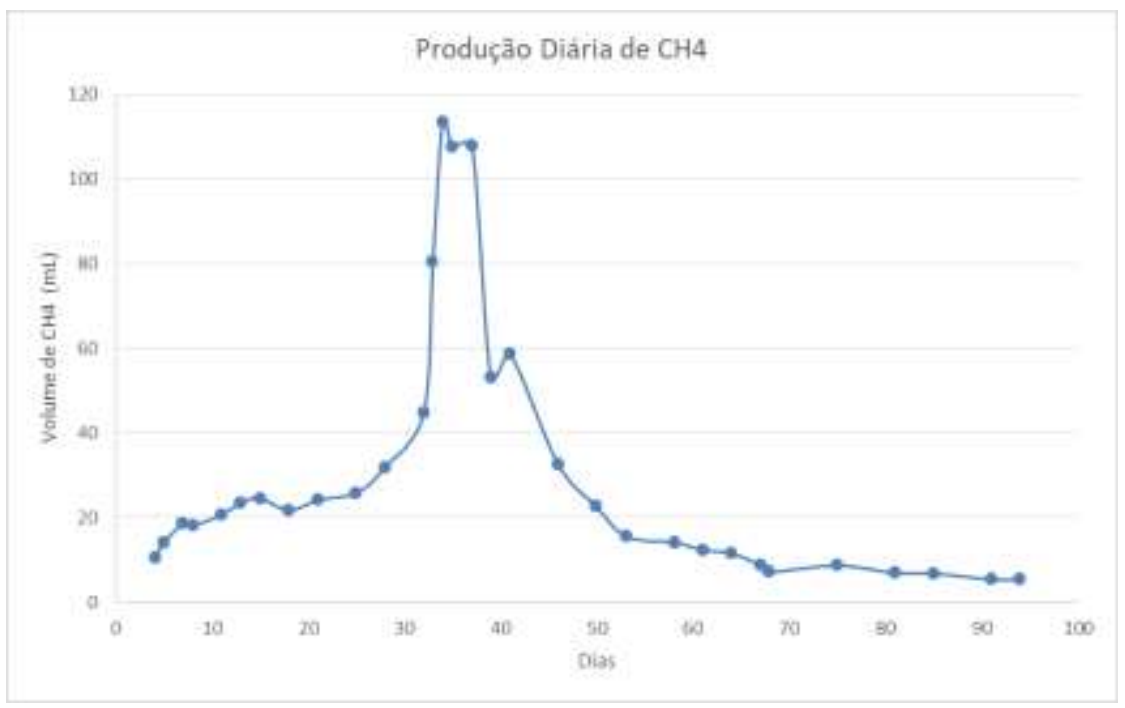

Fonte: Autores (2021).

Os dados experimentais da produção acumulada de metano, obtidos pelas médias dos reatores em triplicata, foram ajustados ao modelo de Gompertz modificado representado pela Equação 3.

$$
H=P \cdot \exp \left\{-\exp \left[\frac{R_{m}}{P} \cdot e \cdot(\lambda-t)+1\right]\right\}
$$

Em que:

$\mathrm{H}$ - produção acumulada de metano $(\mathrm{mL})$;

$\mathrm{P}$ - potencial de produção de metano $(\mathrm{mL})$;

$\mathrm{R}_{\mathrm{m}}$ - taxa de produção máxima de metano $\left(\mathrm{mL} \cdot \mathrm{h}^{-1}\right)$;

$\lambda$ - tempo da fase lag ou tempo mínimo para produzir metano (h);

$\mathrm{t}$ - tempo de incubação do reator $(\mathrm{h})$;

e - número de Euler (2,71828). 
As constantes cinéticas $\mathrm{P}, \mathrm{R}_{\mathrm{m}}$ e $\lambda$ foram determinadas através de regressão não-linear com o uso do software Origin 2020.

O modelo de Gompertz modificado é o mais utilizado para descrever o progresso da produção cumulativa de metano em experimentos em batelada, relacionando-a com o crescimento e o metabolismo microbiano (Ghasemian et al., 2016)

A produção acumulada de metano ao longo do tempo de operação de cada amostra (com e sem inóculo), ajustada ao modelo de Gompertz modificado, podem ser vistas nos gráficos das Figuras 5 e 6 . A comparação entre os volumes acumulados dos reatores com e sem inóculo podem ser vistos na Figura 7.

Figura 5 - Produção acumulada de CH4 ajustada ao modelo de Gompertz modificado - reatores COM Inóculo.

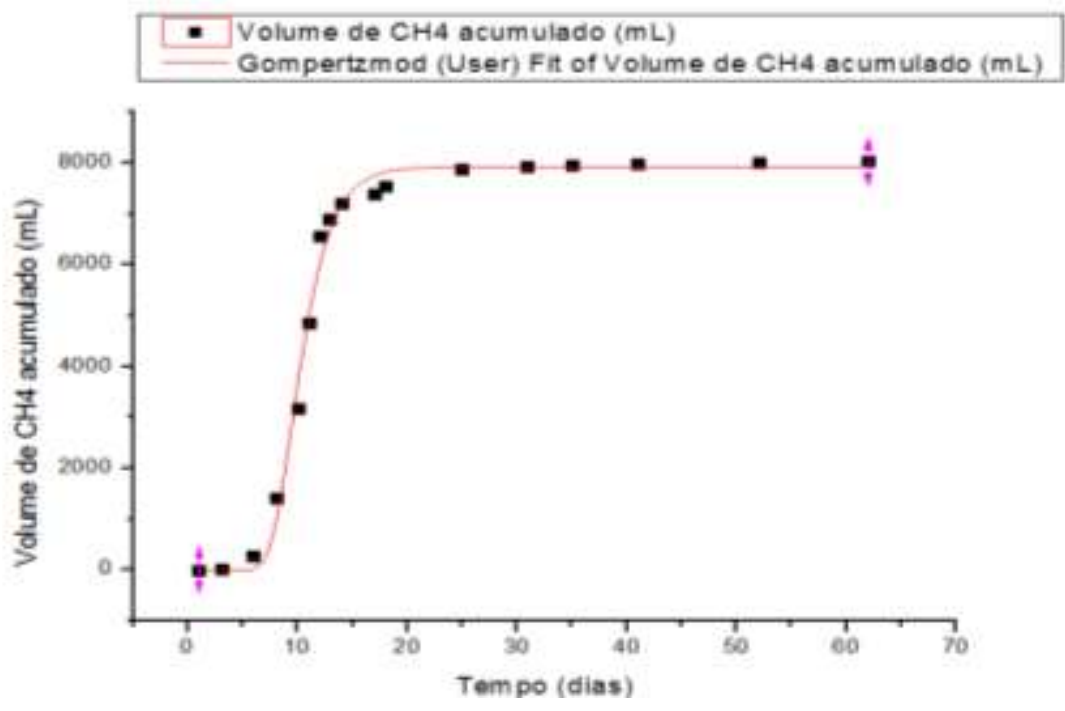

Fonte: Autores (2021).

Figura 6 - Produção acumulada de CH4 ajustada ao modelo de Gompertz modificado - reatores SEM Inóculo.

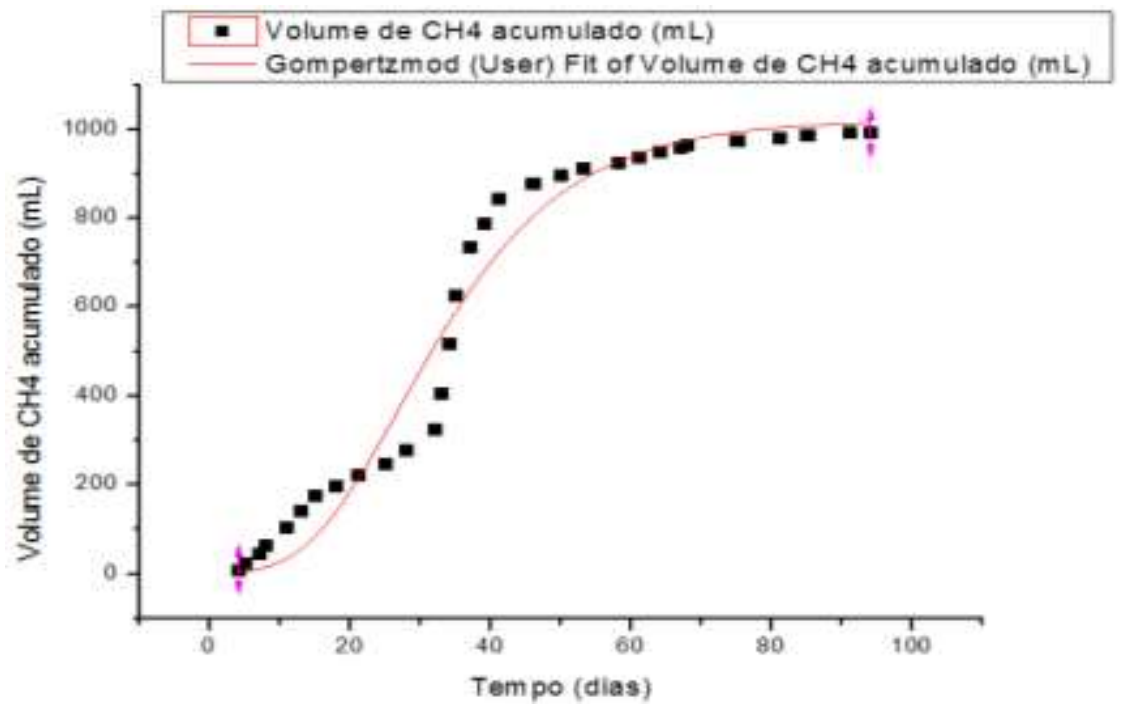

Fonte: Autores (2021). 
Figura 7 - Comparação dos volumes acumulados de CH4 dos reatores COM e SEM o uso de inóculo.

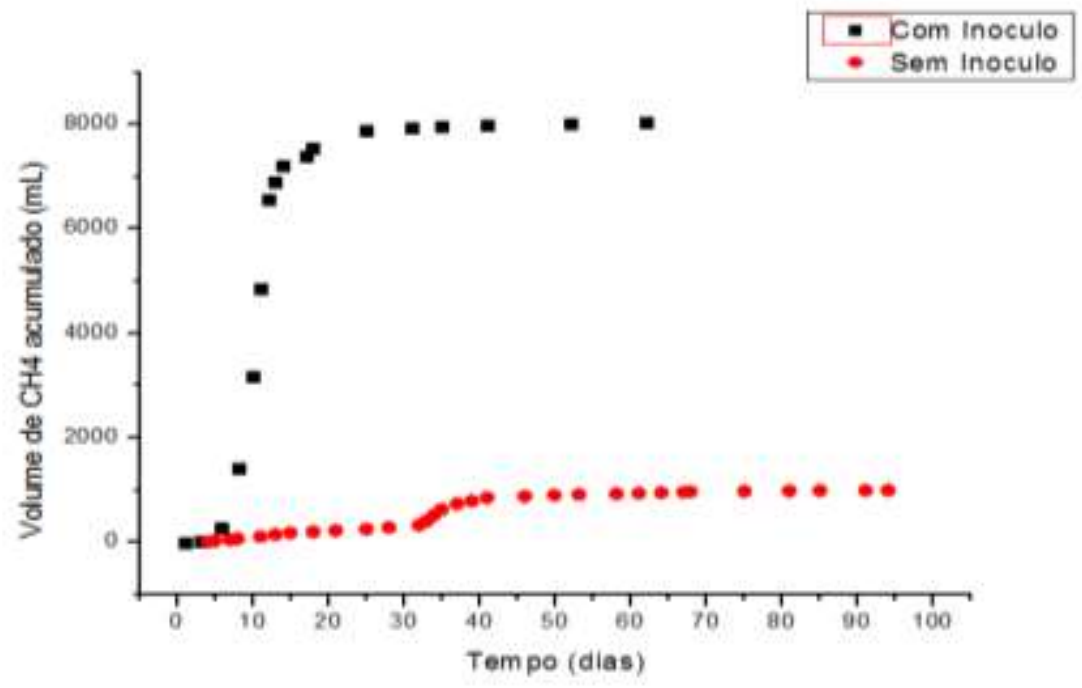

Fonte: Autores (2021).

A partir dos gráficos nas imagens, é possível verificar que os reatores com inóculo produziram os maiores volumes de metano nos primeiros dias de operação, atingindo seu pico de produção próximo ao $10^{\circ}$ dia de operação e atingindo a estabilidade até a sua desativação com quase 70 dias de análise. A produção máxima dos reatores, sem a presença de inóculo, ocorreu mais tardiamente, ao $30^{\circ}$ dia de análise, e continuou crescendo durante todo o período estudado (aproximadamente 100 dias), sem atingir a fase de estabilidade até sua desativação.

As constantes cinéticas do modelo de Gompertz modificado, $\mathrm{P}$ (potencial de produção de metano), $\mathrm{R}_{\mathrm{m}}$ (taxa de produção máxima de metano) e $\lambda$ (tempo da fase lag), foram determinadas através de regressão não-linear e estão dispostas na Tabela 2.

Tabela 2 - Constantes cinéticas do modelo de Gompertz modificado e valores de R².

\begin{tabular}{ccccc}
\hline Reator & $\begin{array}{c}\text { Potencial de produção de } \\
\text { metano }(\mathrm{mL})\end{array}$ & $\begin{array}{c}\text { Taxa de produção máxima de } \\
\text { metano }\left(\mathrm{mL} \cdot \mathrm{h}^{-1}\right)\end{array}$ & $\begin{array}{c}\text { Tempo da fase } \\
\text { lag }(\mathrm{h})\end{array}$ & $\mathrm{R}^{2}$ \\
\hline 1,2 e 3 & 7926,31 & 1491,16 & 7,56 & 0,99192 \\
4,5 e 6 & 1020,42 & 28,40 & 13,90 & 0,99635 \\
\hline
\end{tabular}

Fonte: Autores (2021).

Segundo Ghasemian, et al., (2016), o modelo de Gompertz modificado pode ser considerado eficaz no ajuste dos dados experimentais se todas as análises apresentarem coeficientes de determinação ajustados $\left(R^{2}\right)$ maiores que 0,95 . As curvas dos reatores com e sem inóculo atenderam a esse requisito.

Verificou-se que o maior potencial foi observado nos reatores 1, 2 e 3 (com a presença de inóculo) de 7926,31 mL, que obteve também a maior taxa de produção de metano de 1491,16 mL.h ${ }^{-1}$. Os reatores 4, 5 e 6 (sem inóculo) obtiveram um menor potencial e taxa de produção de metano, $1020,42 \mathrm{~mL}$ e $28,40 \mathrm{~mL} \cdot \mathrm{h}^{-1}$. Observou-se também que as composições com as maiores taxas de produção de metano (Reatores 1, 2 e 3) foram aquelas que, de acordo com a Tabela 1, tiveram as menores durações de operação.

Os tempos de fase lag dos reatores mostram que houve uma rápida adaptação da cultura microbiana às condições experimentais, com tempos variando de 7,5594h a $13,9065 \mathrm{~h}$. 


\section{Conclusão}

$\mathrm{O}$ aterro sanitário, construído para receber os resíduos dos municípios do agreste alagoano, apresenta potencial para geração de energia renovável através da digestão anaeróbia da sua fração orgânica. Os resultados da pesquisa mostraram que o uso de inóculo, para condições ótimas de degradação, reduziu o tempo de estabilização anaeróbia dos resíduos, influenciou no tempo de inicialização do processo, além de ter proporcionado um potencial de produção de metano aproximadamente 8 vezes maior do que sem o uso de inóculo, e uma taxa de produção máxima de metano, por hora, 53 vezes maior do que sem o inóculo.

Esses dados mostram que a fração orgânica do aterro pode ser tratada com intuito de aumentar a sua vida útil, reduzir os impactos ao meio ambiente e servir para aproveitamento energético sustentável.

Como sugestão para futuros trabalhos, sugere-se a utilização de outros tipos de inóculo a fim de identificar qual apresenta maior influência na geração de gás metano a partir da digestão anaeróbia da matéria orgânica de resíduos sólidos em aterros sanitários.

\section{Referências}

Chernicharo, C. A. L. (1997). Princípios do Tratamento Biológico de Águas Residuárias - Vol. 5 - Reatores Anaeróbios: Segrac.

Costa, M. S. S. M., Lucas Júnior, J., Costa, L. A. M., \& Orrico, A. C. A. (2016). A highly concentrated diet increases biogas production and the agronomic value of young bull's manure. Waste Management. 48, 521-7. 10.1016/j.wasman.2015.09.038

Chynoweth, D. P., et al. (1993). Biochemical methane potential of biomass and waste feedstocks. Biomass and bioenergy. 5 (1), 95-111. 10.1016/09619534(93)90010-2

Dai, X., et al. (2016). Simultaneous enhancement of methane production and methane content in biogas from waste activated sludge and perennial ryegrass anaerobic co-digestion: the effects of $\mathrm{pH}$ and $\mathrm{C} / \mathrm{N}$ ratio. Bioresource technology. 216, 323-330. 10.1016/j.biortech.2016.05.100

Damrongsak, D., Chaichana, C., \& Wongsapai, W. (2017). Small-Scale Biogas Plant from Swine Farm in Northern Thailand. 165- 9. 10.1016/j.egypro.2017.11.031

De Souza, M. E. (1984). Fatores que influenciam a digestão anaeróbia. Revista DAE. 44 (137), 88-94. https://www.cetesb.sp.gov.br/biogas/wpcontent/uploads/sites/3/2014/11/revista_dae_vol44_n137_1984.pdf/

Dixon, P. J., et al. (2019). Effect of Substrate to Inoculum Ratio on Bioenergy Recovery from Food Waste, Yard Waste, and Biosolids by High Solids Anaerobic Digestion. Environmental Engineering Science. 36(12), 1459-1465. 10.1089/ees.2019.0078

Edwiges, T., et al. (2020). Methane potential of fruit and vegetable waste: an evaluation of the semi-continuous anaerobic mono-digestion. Environmental technology. 41(7), 921-930. 10.1080/09593330.2018.1515262

Gao, M., et al. (2019). Biogas potential, utilization and countermeasures in agricultural provinces: A case study of biogas development in Henan Province, China. Renewable and Sustainable Energy Reviews. 99, n. May 2018, 191-200. 10.1016/j.rser.2018.10.005

Ghasemian, M., Zilouei, H., \& Asadinezhad, A. (2016). Enhanced Biogas and Biohydrogen Production from Cotton Plant Wastes Using Alkaline Pretreatment. Energy \& Fuels. 30 (12), 10484-10493. 10.1021/acs.energyfuels.6b01999

Gueri, M. V. D., et al. (2017). Digestão anaeróbia de resíduos alimentares utilizando ensaios bmp. BIOFIX Scientific Journal. 3(1), 08-16. 10.5380/biofix.v3i1.55831

Haryanto, A., Hasanudin, U., Chandra, A., \& Iskandar, Z. (2018). Biogas production from anaerobic codigestion of cowdung and elephant grass (Pennisetum purureum) using batch digester. IOP Conference Series: Earth and Environmental Science. 141. 10.1088/1755-1315/141/1/012011

Lima, N. C. (2015). Análise de tipos e concentrações de inóculos para potencializar a geração de biogás na digestão anaeróbia da fração orgânica dos resíduos sólidos domiciliares do bairro planalto pici, fortaleza - CE. U.F.C. Dissertação de mestrado. http://www.repositorio.ufc.br/handle/riufc/11597

Liu, G., et al. (2011). Influence of pH adjustment and inoculum on anaerobic digestion of kitchen waste for biogas producing. Journal of biobased materials and bioenergy. 5(3), 390-5. 10.1166/jbmb.2011.1161

Machado, L. R., et al. (2018). O estado da arte da digestão anaeróbia de soro de leite e de dejetos da suinocultura para produção de biogás. Revista Tecnológica. 27(1), 104-119. 10.4025/revtecnol.v27i1.45520

Magalhães, G. V. V. (2018). Avaliação da biodigestão anaeróbia de resíduos orgânicos: ensaios de potencial bioquímico de metano (BMP) e projeto piloto de um biodigestor em escala real. Tese de Doutorado, Pós Graduação em Engenharia Civil, Universidade Federal do Ceará - UFC. http://www.repositorio.ufc.br/handle/riufc/34759

Maintinguer, S. I., et al. (2008). Fermentative hydrogen production by microbial consortium. International Journal of Hydrogen Energy. 33 , $4309-4317$. 10.1016/j.ijhydene.2008.06.053 
Research, Society and Development, v. 10, n. 6, e0110615407, 2021

(CC BY 4.0) | ISSN 2525-3409 | DOI: http://dx.doi.org/10.33448/rsd-v10i6.15407

Moraes, B. S., Zaiat, M., \& Bonomi, A. (2015). Anaerobic digestion of vinasse from sugarcane ethanol production in Brazil - Challenges and perspectives. Renewable and Sustainable Energy Reviews. 44, 888-903. 10.1016/j.rser.2015.01.023

Nogueira, C. E. C., et al. (2015). Exploring possibilities of energy insertion from vinasse biogas in the energy matrix of Paraná State , Brazil. Renewable and Sustainable Energy Reviews. 48, 300-5. 10.1016/j.rser.2015.04.023

Rogoff, M. J., \& Screve, F. (2019). Waste-to-energy: technologies and project implementation. Academic Press.

Saidu, M., et al. (2013). Influence of palm oil mill effluent as inoculum on anaerobic digestion of cattle manure for biogas production. Bioresource technology. 141, 174-6. 10.1016/j.biortech.2013.03.111

Steil, L. (2007). Avaliação do uso de inóculos na biodigestão anaeróbia de resíduos de aves de postura, frangos de corte e suínos.108f. Tese de doutorado da Escola de Engenharia de São Carlos, Universidade de São Paulo. http://hdl.handle.net/11449/88047

Xu, F., et al. (2018). Anaerobic digestion of food waste-Challenges and opportunities. Bioresource technology. 247, 1047-1058. 10.1016/j.biortech.2017.09.020 